\title{
The Psychological Condition of Healthcare Professionals during the COVID-19 Pandemic at a Referral Hospital in Southeast Sulawesi, Indonesia
}

\author{
Asbath Said $^{1 *}$, Asri Dwi Novianti ${ }^{1}$, Sartini Risky ${ }^{2}$ \\ ${ }^{1}$ Department of Nursing, Faculty of Health Science, Mandala Waluya University, Kendari, Indonesia; ${ }^{2}$ Department of Public \\ Health, Faculty of Health Science, Mandala Waluya University, Kendari, Indonesia
}

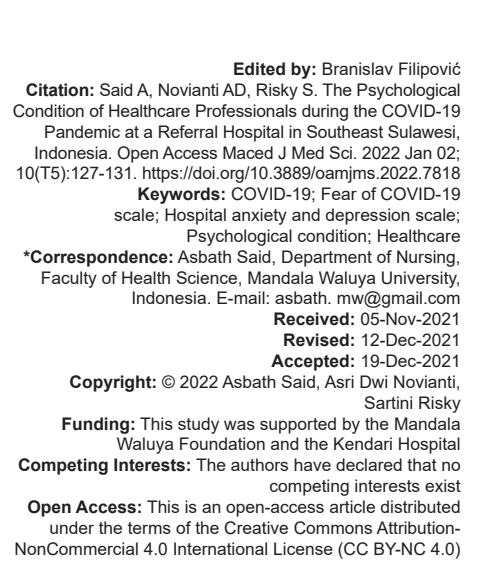

Abstract

BACKGROUND: The significant increase in positive cases of COVID-19 in Indonesia has increased the number of health care personnel, nurses, and physicians who have been exposed to the virus, which raises the psychological burden on health professionals.

AIM: This study aims to analyze the relationship between the psychological responses of health professionals and anxiety/depression in the hospital using the Fear of COVID-19 scales and the hospital anxiety and depression scale, respectively.

METHODS: The method is quantitative with a cross-sectional survey, which uses an online questionnaire involving about 207 health professionals working at the COVID-19 referral hospital.

RESULTS: The result of the Pearson correlation test showed that the highest fear level of health professionals against COVID-19 was $41.5 \%$, while the highest anxiety and depression levels are at the usual level of $76.3 \%$ and $60.4 \%$, respectively. There was a direct relationship between the fear of COVID-19 and anxiety or depression, with significant values of 0.000 or 0.026 , respectively.

CONCLUSIONS: The study showed the significance of the psychological state of health professionals during a pandemic. Therefore, the government must provide mental support to health professionals through counselling and more accurate and up-to-date information.

\section{Introduction}

The emergence of the novel coronavirus also known as COVID-19 started in Wuhan in China [1], which caused a significant impact on all aspects of human life, such as massive economic downturns, job losses, adaptation to all aspects of life, and even death [2]. The World Health Organization declared COVID-19 a global epidemic on March 11, 2020. In addition, this virus is capable of developing and spreading between humans, which led to 27 million cases and 900,000 deaths worldwide from reports in December 6, 2020 [3].

The signs and symptoms of COVID-19 are observed in acute respiratory disorders, such as fever, cough, and shortness of breath, at an average incubation period of 5-6 days and a maximum of 14 days. COVID19 can cause pneumonia, acute respiratory syndrome, kidney failure, and even death in severe cases. In most cases, the symptoms range from fever to difficulty in breathing, and X-rays reveal extensive pneumonia infiltrates in both lungs [4].

The first two COVID-19 cases were reported on March 2, 2020. Subsequently, there were 1285 cases in
30 provinces in March 29, 2020. The most prevalent regions were Jakarta, West Java, Banten, East Java, and Central Java with 675, 149, 106, 90, and 63 cases, respectively [4].

Health care providers who treat COVID19 patients were at risk of developing anxiety and depression. Furthermore, they were the group most at risk of developing psychiatric symptoms during the pandemic, due to risk factors such as being female and working on the frontlines [5].

According to a study of 109 nurses, where intensive care was provided for COVID-19 patients in Canada, they experienced clinical concern (23\%), probability $(13 \%)$, and significant concern $(38 \%)$ in the form of post-traumatic stress disorder symptoms, as well as mild to slightly severe depression ( $57 \%)$, anxiety $(67 \%)$, and stress (54\%). During the interview, anxiety, worry, distress, and fear are all identified as symptoms of psychological distress [6].

A study involving 115 health workers at a tuberculosis treatment center in Anhui, China revealed that about $36.4 \%$ of respondents (mostly nurses) experienced depression while providing treatment 
for COVID-19 [7]. In Singapore, another study was conducted using 3.075 health workers from different departments. The results showed that $31.8 \%$ and $40.7 \%$ experienced depression and anxiety, respectively, using HADS questionnaire [8]. Furthermore, a study was conducted by DASS21 questionnaire using 491 nurses aged between 31 and 56 . The results showed that $8.5 \%$ experienced depression and anxiety simultaneously, while $6.3 \%$ expressed depression only, which varied from fair to acute [9].

The primary stressors for health workers were personal safety concerns, family members, and patient deaths [10]. Lai et al. (2020) conducted a study involving 1257 COVID-19 health workers from 34 hospitals in China, where symptoms of depression, anxiety, sleeplessness, and depression were observed in majority of the population, especially female nurses and health professionals on the front lines. Therefore, psychological assistance or intervention was required [11].

There has been no consideration of the mental health of health workers who treat COVID-19 patients, such as professional associations, health service agencies, or even individual nurses, because they are overburdened with patient care to the point where their mental health becomes disturbed. Therefore, there is the need for interventions and recommendations to resolve this dilemma since health workers will provide optimal service to patients when they are mentally and physically healthy.

Subsequently, this study is not concurrent with previous studies since the use of FCS-19 is still very finite. Such study is specialized for hospitals where personal protective equipment is still limited.

The purpose of this study is to analyze the relationship between psychological responses of health workers on anxiety and depression in hospitals using the Fear of COVID-19 scale and the hospital anxiety and depression scale (HADS).

\section{Methods}

\section{Research design}

The method is quantitative with a crosssectional survey approach, and it uses an Indonesiatranslated questionnaire namely the COVID-19 Fear Scale [12] (FCV-19S). Furthermore, it is an Indonesian version that comprises seven scale items manufactured to gauge the fear of COVID-19. The validation has been examined with a Cronbach value of (FCV-19-I) 0.819 with good internal reliability [12]. Meanwhile, the reliability for anxiety and depression scale (HADS) has been examined with coefficient value kappa of 0.076 and 0.681 for sub-scale of anxiety and depression [13].
The Fear of COVID-19 scale [12] and the HADS [13] were used in this study, as well as a questionnaire translated to Indonesian.

\section{Data collection technique}

The samples were health workers from Kendari referral hospital including nurses, doctors, midwives, and other health professionals. The sampling technique employed was convenience (non-probability) sampling, and the data were collected online using Google Forms, which required the use of informed consent at the start of the online questionnaire, including an explanation, purpose, participants, anonymity, and volunteer's response.

This study was conducted according to the Helsinki's Declaration and was approved by The Human Subject Review Board, Mandala Waluya University (Number: 025/KE-UMW/XI/2020) before the survey. Furthermore, the data of the respondents were saved on a personal computer, which was only accessed by the observer.

An online questionnaire was distributed to 207 respondents who are health workers between the $12^{\text {th }}$ to the $18^{\text {th }}$ of December, 2020.,

\section{Results}

This study included 207 health workers from the COVID-19 referral hospital in Kendari, Southeast Sulawesi. The demographics comprised 162 females and 45 males at $78.3 \%$ and $21.7 \%$, respectively. The majority of the respondents were between the ages of 21 and 30 years at $48.8 \%$ and $92.8 \%$, respectively, as demonstrated in Table 1.

Table 1 shows the percentage of the anxiety level of respondents. The highest anxiety is at the normal level of 125 respondents $(60.4 \%)$, and the lowest at the severe level of 5 respondents (2.4\%).

Then, for the percentage of respondents' depression levels, the highest is in the normal category of 158 respondents $(76.3 \%)$ and the lowest is in a severe category of 2 respondents (1.0\%).

Based on the research results, the highest fear is in the quiet fear category of 86 respondents $(41.5 \%)$ while the lowest is a very fear category of 6 respondents (22.2\%) (Table 1).

Furthermore, the data normality test is carried out to determine the type of statistical analysis used. The Kolmogorov-Smirnov test was used to test for normality. The results showed that the data distribution was skewed based on the 3 variables examined. Therefore, the non-parametric 
Table 1: Respondent characteristics

\begin{tabular}{|c|c|c|}
\hline Characteristics of Respondents & $\mathrm{n}$ & $\%$ \\
\hline \multicolumn{3}{|l|}{ Sex } \\
\hline Male & 45 & 21.7 \\
\hline Female & 162 & 78.3 \\
\hline \multicolumn{3}{|l|}{ Education Level } \\
\hline S2 & 1 & 0.5 \\
\hline $\mathrm{s} 1$ & 187 & 90.3 \\
\hline D3 & 19 & 9.2 \\
\hline \multicolumn{3}{|l|}{ Marital Status } \\
\hline Married & 63 & 30.4 \\
\hline Single & 144 & 69.6 \\
\hline \multicolumn{3}{|l|}{ Age } \\
\hline $21-30$ years old & 101 & 48.8 \\
\hline $31-40$ years old & 28 & 13.5 \\
\hline $41-50$ years old & 30 & 14.5 \\
\hline$>50$ years old & 48 & 23.2 \\
\hline \multicolumn{3}{|l|}{ Profession } \\
\hline Nurse & 192 & 92.8 \\
\hline Midwife & 8 & 3.9 \\
\hline Doctor & 2 & 1 \\
\hline Other health workers & 5 & 2.4 \\
\hline \multicolumn{3}{|l|}{ Anxiety Level } \\
\hline Normal & 125 & $60.4 \%$ \\
\hline Mild & 54 & $26.1 \%$ \\
\hline Moderate & 23 & $11.1 \%$ \\
\hline Severe & 5 & $2.4 \%$ \\
\hline \multicolumn{3}{|l|}{ Depression Level } \\
\hline Normal & 158 & $76.3 \%$ \\
\hline Mild & 39 & $18.8 \%$ \\
\hline Moderate & 8 & $3.9 \%$ \\
\hline Severe & 2 & $1.0 \%$ \\
\hline \multicolumn{3}{|l|}{ Fear Level } \\
\hline Not fear & 8 & $3.9 \%$ \\
\hline Less fear & 61 & $29.5 \%$ \\
\hline Quite Fear & 86 & $41.5 \%$ \\
\hline Fear & 46 & $22.2 \%$ \\
\hline Very Fear & 6 & $2.9 \%$ \\
\hline
\end{tabular}

Spearman correlation test was carried out, as shown in Table 2.

Table 2: Correlation of depression, anxiety, and fear of COVID-19

\begin{tabular}{llllll}
\hline & & Depression & Anxiety & Fear \\
\hline Spearman's Rho & Depression & Correlation Coefficient & 1.000 & $0.196^{* *}$ & $0.154^{*}$ \\
& & Sig. (2-tailed) & 0.00 & 0.005 & 0.026 \\
& $N$ & 207 & 207 & 207 \\
& Anxiety & Correlation Coefficient & $0.196^{* *}$ & 1.000 & $0.374^{* *}$ \\
& & Sig. (2-tailed) & 0.005 & 0.00 & 0.000 \\
& \multirow{4}{*}{ Fear } & N & 207 & 207 & 207 \\
& Correlation Coefficient & $0.154^{*}$ & $0.374^{\star *}$ & 1.000 \\
& Sig. (2-tailed) & 026 & 0.000 & 0.00 \\
& $\mathrm{~N}$ & 207 & 207 & 207 \\
\hline${ }^{*}$ Correlation is significant at the & 0.05 level (2-tailed). & & &
\end{tabular}

According to Table 2, the correlation coefficient between depression and fear of COVID-19 was 0.154 based on the Spearman correlation test, which indicated that there was a low degree of association between depression and the fear of COVID-19. Furthermore, the correlation coefficient was positive, which indicated a unidirectional relationship between the two variables. Therefore, there was an increased fear of COVID-19 in depressed health care workers. Table 2 showed that the significant 2-tailed value for depression and the fear of COVID-19 was 0.026 , which indicated that there was a significant relationship between depression and the fear of COVID-19 at a significant value $<0.05$.

The result of the Spearman correlation test showed that the correlation coefficient between anxiety and the fear of COVID-19 was 0.374 . Furthermore, this implied that there was a strong relationship between anxiety and the fear of COVID-19. The relationship between the two variables was unidirectional since the correlation coefficients were positive. Therefore, there was an increased fear of COVID-19 in anxious health workers. Table 2 showed that the Significant 2-tailed value between anxiety and the fear of COVID-19 was 0.000 , which indicated a relationship between anxiety and the fear of COVID-19 at a significant value $<0.05$.

\section{Discussion}

The COVID-19 epidemic started in Indonesia for more than a year, infecting and killing a large number of people and instilling fear in everyone, including health-care workers [10], [14]. During the pandemic, there was a health crisis, which increased the risks in hospitals [15]. Furthermore, there was a significant increase in the number of patients admitted to hospital, which increased the work pressure on healthcare workers [16]. Health care workers were anxious and uncomfortable while in the hospital due to the high number of their colleagues who have died from COVID-19 and the fear of transmitting the virus to their families [16].

According to a study conducted by (Tan et al., 2020) on 500 health workers in two hospitals in Singapore, $68 \%$ are anxious at work during the pandemic[17]. Similarly, a study conducted on 544 health workers from 21 provinces in Indonesia by (Sanjaya et al., 2021) discovered that $28.1 \%$ and $22.8 \%$ experience anxiety and depression, respectively [14].

In this research with the HADS scale, from 207 respondents, $23.7 \%$ of the respondents experience depression from mild to severe levels. During the pandemic, exciting things became unappealing, and people no longer cared about their beauty as much as they used to. However, in this study, $60.4 \%$ of anxiety is typical, and $76.3 \%$ do not experience depression, which could be related to pandemic adaptability and resilience since the data collection is completed at the end of 2020. This study was supported by psychological endurance in which people can be recovered from negative emotion [18] and back to normal life [19].

According to Bozdag and Ergun, 2020, 214 health workers in several hospitals in Turkey showed improved psychological resilience while working during the COVID-19 pandemic, such as improved sleep quality and pleasant feelings [20].

The fear of COVID-19, on the other hand, is still slightly high. According to the findings, $41.5 \%$ of the respondents are quite fear, $22.2 \%$ are fear, $2.9 \%$ are very fearful, and $29.5 \%$ are less fear.

The COVID-19 pandemic has been occurring for more than 1 year, and health workers are still experiencing negative stigma and social rejection [21]. This contributes to the fear of health workers [22]. Moreover, this study on COVID-19 and other mental 
issues such as anxiety, depression, fatigue, and stress showed that the disease susceptibility can cause fear and anxiety to nurses. The level of their performance will be affected when this occurs [23], [24].

As demonstrated by Spearman correlation analysis values of 0.000 and 0.026 , the presence of anxiety and depression symptoms, respectively, described in this study shows a significant relationship with fear of COVID-19. This conclusion indicates that psychological distress, anxiety, and depression, are still felt by health workers, since they are related to their profession, particularly nurses who are at the forefront of caring for COVID-19 patients. Therefore, they are physically and psychologically motivated to provide quality nursing care to patients [17], [25].

Another study on nurses in Pakistan found that the fear of COVID-19 causes secondary trauma and psychological stress [26]. The most common mental changes associated with health workers include fear, anxiety, and depression, which were more intense during the pandemic since they were on the front lines trying to reduce the outbreak [27]. The performance level of health workers was significantly higher than before the pandemic [28]. Furthermore, they lacked self-defense equipment [29] and were plagued by negative issues with less support from mental health professionals [30], [31].

Further study is recommended to ascertain the direction of the significant correlation between the fear of COVID-19, anxiety and depression, as well as to determine how the fear of COVID-19 may affect the practice of health protocol measures. In addition, it is recommended that this further study employs the use of samples from several referral COVID-19 hospitals.

\section{Conclusion}

According to this study, there was a significant association and a direct relationship between the fear of COVID-19, anxiety and depression among health workers during the pandemic. Therefore, health workers require special attention and assistance to ensure that they are always physically and psychologically healthy to deliver excellent health services to the community.

\section{Acknowledgments}

The authors are grateful to the mandala waluya foundation and the kendari hospital for providing sponsorship and data information for the accomplishment of the objective of this study.

\section{References}

1. Li J, Gong X, Wang Z, Chen R, Li T, Zeng D, Li M. Clinical features of familial clustering in patients infected with 2019 novel Coronavirus in Wuhan, China. Virus Res. 2020;286:198043. https://doi.org/10.1016/j.virusres.2020.198043

PMid:32502551

2. Hu Y, Sun J, Dai Z, Deng H, Li X, Huang Q, et al. Prevalence and severity of Corona virus disease 2019 (COVID-19): A systematic review and meta-analysis. J Clin Virol. 2020;127:104371. https:// doi.org/10.1016/j.jcv.2020.104371

PMid:32315817

3. Freitas ARR, Napimoga M, Donalisio MR. Assessing the severity of COVID-19. Epidemiol Serv Saude. 2020;29(2):e2020119. https://doi.org/10.5123/S1679-49742020000200008

PMid:32267300

4. Holshue ML, DeBolt C, Lindquist S, Lofy KH, Wiesman J, Bruce $\mathrm{H}$, et al. First case of 2019 novel Coronavirus in the United States. N Engl J Med. 2020;382(10):929-36. https://doi. org/10.1056/NEJMoa2001191

PMid:32004427

5. Crowe S, Howard AF, Vanderspank-Wright $B$, Gillis $P$, McLeod F, Penner C, et al. The effect of COVID-19 pandemic on the mental health of Canadian critical care nurses providing patient care during the early phase pandemic: A mixed method study. Intensive Crit Care Nurs. 2021;63:102999. https://doi. org/10.1016/j.iccn.2020.102999

PMid:33342649

6. Vindegaard N, Benros ME. Since January 2020 Elsevier has created a COVID-19 resource centre with free information in English and Mandarin on the novel coronavirus COVID-19. The COVID-19 resource centre is hosted on Elsevier connect, the company's public news and information. Brain Behav Immun. 2020;89:531-42.

7. Fang $X H$, Wu L, Lu LS, Kan XH, Wang $H$, Xiong YJ, et al. Mental health problems and social supports in the COVID-19 healthcare workers: A Chinese explanatory study. BMC Psychiatry. 2021;21(1):34. https://doi.org/10.1186/s12888-020-02998-y PMid:33435867

8. Tan BY, Kanneganti A, Lim LJ, Tan M, Chua YX, Tan L, et al. Burnout and associated factors among health care workers in Singapore during the COVID-19 pandemic. J American Med Directors Assoc. 2020;21:1751-8.

9. Marthoenis M, Fathiariani L, Nassimbwa J. Investigating the burden of mental distress among nurses at a provincial COVID-19 referral hospital in Indonesia: A cross-sectional study. BMC Nurs. 2021;20(1):1-8. https://doi.org/10.1186/ s12912-021-00596-1

10. Cai H, Tu B, Ma J, Chen L, Fu L, Jiang Y, et al. Psychological impact and coping strategies of frontline medical staff in Hunan between January and March 2020 during the outbreak of Coronavirus disease 2019 (COVID-19) in Hubei, China. Med Sci Monit. 2020;26:e924171. https://doi.org/10.12659/MSM.924171 PMid:32291383

11. Lai J, Ma S, Wang $\mathrm{Y}$, Cai Z, Hu J, Wei N, et al. Factors associated with mental health outcomes among health care workers exposed to Coronavirus disease 2019. JAMA Netw Open. 2020;3(3):e203976. https://doi.org/10.1001/ jamanetworkopen.2020.3976

PMid:32202646

12. Kassim MA, Ayu F, Kamu A, Pang NT, Ho CM, Algristian H, et al. Indonesian version of the fear of COVID-19 scale: Validity and reliability. Borneo Epidemiol J. 2020;1(2):124-35.

13. Rudy M, Widyadharma PE, Adnyana O. Reliability Indonesian 
Version of the Hospital Anxiety and Depression Scale (HADS) of Stroke Patients in Sanglah General Hospital Denpasar, Research Gate; 2015.

14. Sunjaya DK, Herawati DM, Siregar AY. Depressive, anxiety, and burnout symptoms on health care personnel at a month after COVID-19 outbreak in Indonesia. BMC Public Health. 2021;21(1):227. https://doi.org/10.1186/s12889-021-10299-6 PMid:33509159

15. Birkmeyer JD, Barnato A, Birkmeyer N, Bessler R, Skinner J. The impact of the COVID-19 pandemic on hospital admissions in the United States. Health Aff (Millwood). 2020;39(11):2010-7. https://doi.org/10.1377/hlthaff.2020.00980

PMid:32970495

16. Ornell F, Halpern SC, Kessler FH, Narvaez JC. The impact of the COVID-19 pandemic on the mental health of healthcare professionals. Cad Saude Publica. 2020;36(4):e00063520. https://doi.org/10.1590/0102-311X00063520 PMid:32374807

17. Tan BY, Chew NW, Lee GK, Jing M, Goh Y, Yeo LL, et al. Psychological impact of the COVID-19 pandemic on health care workers in Singapore. Ann Intern Med. 2020;173(4):317-20. https://doi.org/10.7326/M20-1083 PMid:32251513

18. Karaar B, Canli D. Psychological resilience and depression during the COVID-19 pandemic in Turkey. Psychiatr Danub. 2020;32(2):273-9. https://doi.org/10.24869/psyd.2020.273 PMid:32796798

19. Heath C, Sommerfield A, von Ungern-Sternberg BS. Resilience strategies to manage psychological distress among healthcare workers during the COVID-19 pandemic: A narrative review. Anaesthesia. 2020;75(10):1364-71. https://doi.org/10.1111/ anae. 15180 PMid:32534465

20. Bozdağ F, Ergün N. Psychological resilience of healthcare professionals during COVID-19 pandemic. Psychol Rep. 2021;124(6):2567-86. https://doi. org/10.1177/0033294120965477 PMid: 33050800

21. Lenzo V, Quattropani MC, Sardella A, Martino G, Bonanno GA. Depression, anxiety, and stress among healthcare workers during the COVID-19 outbreak and relationships with expressive flexibility and context sensitivity. Front Psychol. 2021;12:623033. https://doi.org/10.3389/fpsyg.2021.623033 PMid:33692724

22. Luceño-Moreno L, Talavera-Velasco B, García-Albuerne Y, MartínGarcía J. Symptoms of posttraumatic stress, anxiety, depression, levels of resilience and burnout in Spanish health personnel during the COVID-19 pandemic. Int J Environ Res Public Health. 2020;17(15):5514. https://doi.org/10.3390/ijerph17155514 PMid:32751624

23. Mo $Y$, Deng L, Zhang L, Lang Q, Liao C, Wang N, et al. Work stress among Chinese nurses to support Wuhan in fighting against COVID-19 epidemic. J Nurs Manag. 2020;28(5):10029. https://doi.org/10.1111/jonm.13014 PMid:32255222

24. Catton H. Nursing in the COVID-19 pandemic and beyond: Protecting, saving, supporting and honouring nurses. Int Nurs Rev. 2020;67(2):157-9. https://doi.org/10.1111/inr.12593 PMid:32578250

25. Sampaio F, Sequeira C, Teixeira L. Nurses' mental health during the COVID-19 outbreak: A cross-sectional study. J Occup Environ Med. 2020;62(10):783-7. https://doi.org/10.1097/ JOM.0000000000001987 PMid:32769803

26. Khattak SR, Saeed I, Rehman SU, Fayaz M. Impact of fear of COVID-19 pandemic on the mental health of nurses in Pakistan. J Loss Trauma. 2020;26:1-15.

27. Labrague LJ, de Los Santos JA. Fear of COVID-19, psychological distress, work satisfaction and turnover intention among frontline nurses. J Nurs Manag. 2021;29(3):395-403.

28. Maunder R. The experience of the 2003 SARS outbreak as a traumatic stress among frontline healthcare workers in Toronto: Lessons learned. Philos Trans R Soc Lond B Biol Sci. 2004;359(1447):1117-25. https://doi.org/10.1098/ rstb.2004.1483

PMid:15306398

29. Alnazly E, Khraisat OM, Al-Bashaireh AM, Bryant CL. Anxiety, depression, stress, fear and social support during COVID-19 pandemic among Jordanian healthcare worker. PLoS One. 2021;16(3):e0247679. https://doi.org/10.1371/journal. pone. 0247679 PMid:33711026

30. Que J, Shi L, Deng J, Liu J, Zhang L, Wu S, et al. Psychological impact of the COVID-19 pandemic on healthcare workers:Acrosssectional study in China. Gen Psychiatr. 2020;33(3):e100259. https://doi.org/10.1136/gpsych-2020-100259 PMid:32596640

31. Li S, Wang Y, Xue J, Zhao N, Zhu T. The impact of COVID-19 epidemic declaration on psychological consequences: A study on active Weibo users. Int $\mathrm{J}$ Environ Res Public Health. 2020;17(6):2032. https://doi.org/10.3390/ijerph17062032 PMid:32204411 